Article

\title{
Feasibility Assessment of Two Biogas-Linked Rural Campus Systems: A Techno-Economic Case Study
}

\author{
Liqin Zhu ${ }^{1,2}$ and Congguang Zhang ${ }^{3, *}$ \\ 1 School of Marxism, Hohai University, Nanjing 210098, China; lqzhu@hhu.edu.cn \\ 2 State Key Laboratory of Hydrology-Water Resources and Hydraulic Engineering, Hohai University, \\ Nanjing 210098, China \\ 3 Yangling Tuojiang Agricultural Technology Co. LTD, Shaanxi 712100, China \\ * Correspondence: qaulxxj@hotmail.com; Tel.: +1-614-772-9699
}

Received: 6 January 2020; Accepted: 29 January 2020; Published: 5 February 2020

check for updates

\begin{abstract}
The principle of sustainable development is becoming more and more prominent in various schools, and the eco-campus in rural areas often has more room for display. The identification and assessment of cost-effective biomass resources appropriate for recycling represent an opportunity that may significantly improve the comprehensive efficiency of an eco-campus system, resulting in remarkable investment savings, pollution reduction, as well as reducing energy consumption and resources waste. The economic feasibility of two biogas-linked rural campus systems (Fanjiazhai Middle School, FJZ and Xidazhai Middle School, XDZ, Yangling, China), as well as their key technologies, is investigated, the two systems respectively represent two biobased agricultural production modes. It is found that the initial investment, operating investment, and total revenue of FJZ system is 1.37 times, 2.39 times, and 1.71 times of XDZ system respectively, thus indicating that FJZ campus is proved to be a "larger" system compared to the other one. The operating costs show that reasonable control of labor and transportation costs should be carried out to optimize the economic feasibility of the system. After considering the system's economic credits obtained from using biogas slurry flushing system and avoiding waste management, the net present value of XDZ system had increased to its 1.5 times, while the FJZ system had increased to its $135 \%$. From the perspective of revenue to investment ratio, XDZ system has a better profit earning efficiency compared to FJZ system. The sensitivity analysis indicates that biogas price, fruit yield, labor use are main factors that have the greatest impacts on the economic performance of these eco-campuses.
\end{abstract}

Keywords: techno-economic analysis; eco-campus; sustainable development; biomass conversion

\section{Introduction}

During the process of industrialization in the past few decades, the environment in many parts of the world has been severely damaged. To facilitate today's sustainable society, protecting the environment and achieving harmonious coexistence with the environment are common issues facing all mankind [1]. As an important part of the earth environment, the campus is a special community. In China, hundreds of millions of students and faculties are living and working on campus every day. The environment of the campus not only affects the learning and living of the people in the school, the energy and resources consumed by the campus during daily operation will also affect the surrounding communities and even the wider range of environment [2]. Since the campus is a place for students to acquire knowledge, form positive spirit values and good behaving habits, through the visual environment of the campus, the teaching environment, school life, and management system are conveying the concept of environmental protection, which is essential for the future careers of students. And by allowing students recognizing the importance of environment protection, the policymakers 
can not only help the campus itself become "greener", but also promote the sustainable development of the entire society in the future.

According to the survey, many countries have been taking actions on the sustainable development of schools for a long time. For instance, in the United States, campuses have experienced three different eras of sustainable development: green campuses (1970s-1990s), sustainable development of campuses (1990s-2010s) as well as implementation of sustainability on and off campuses (2010s-) [3]. Due to special weather conditions, the UAE is developing green campuses for energy consumption, especially for campus buildings [4]. Brazil has incorporated environmental management issues into the daily teaching activities of higher education institutions and actively disseminated the concept of sustainable development [5]. The ecological campus construction in these countries focuses on the dissemination of ideas, propaganda, and education. However, China's ecological campus begins with ecological technology demonstration and facility energy management [6]. Since the 2000s, the Chinese government has provided financial support, and built a campus energy management system (CEMS), implemented energy transformation and water conservation projects, and vigorously applied green technology to campus construction and operation management to build an energy and resource-saving campus [7]. In 2008, the "Building a Sustainable Campus Seminar" organized by the Ministry of Education was held at Tongji University, the leaders of the top 32 universities in China signed the "Tongji Declaration" with a broader concept of sustainable development [8]. The national standard "Green Campus Evaluation Standard" implemented on 1 October 2019 will serve as the technical basis for the development of green campus evaluation in China and promote the sustainable development of various campuses [9].

Every day, a large amount of human and kitchen waste is produced in schools, which is a problem that needs to be effectively solved. In rural areas, in order to deal with these organic wastes and turn these wastes into valuable resources, many decision makers have introduced multiple biogas technologies into the campus and combined with agricultural production techniques [10]. To create a small circulating system in the campus, such system is often called the "breeding-biogas-planting compound system", and these systems have played a good demonstration in the sustainable development of the campus [10]. However, given the constraints of school planning and local available resources, it is usually difficult to form a modeled small-scale recycling system inside a campus. For example, in cities, it is hard for the government to approve a school to plan a small farm internally due to the expensive urban land. However, in rural areas of China, due to the flexibility of land planning and wider space, schools have a greater possibility to carry out more flexible campus planning and pattern exploration, and promote the circular agricultural model, it is easier to form the above-mentioned ecological composite system.

At present, various methods have been proposed to assess the sustainability of ecological campuses, including economic, social and environmental characteristics of them. For example, some scholars have used multi-objective linear programming (MOLP) and fuzzy two-stage algorithm [11] to plan the campus's energy system to reduce $\mathrm{CO}_{2}$ emissions and energy waste. Many scientists have analyzed the carbon footprint of the campus systems by using the life cycle analysis (LCA) method to determine the main sources of greenhouse gas emissions from the campuses [12-14] and provided valuable suggestions for the sustainable development of these campuses [15]. Gu et al. used the University of Keele to quantify the relationship between environmental factors including water, energy, food, waste and carbon emissions [16], which was used to monitor sustainability performance and improve the university members' environmental awareness $[17,18]$. In general, these methods focus more on the ecological and environmental impacts of the campus, but the economic performance of the campus is a fundamentally most concerned factor, but it is rarely involved.

Techno-economic analysis usually uses a variety of tools or models to simulate a system, assesses the technical or economic feasibility, and may find the bottleneck inside the project [19]. This approach is also an effective means of assessing the benefits and costs of various production technologies [20]. Even though the raw materials for these production technologies may be renewable, the production process 
should also be as economically viable and environmentally sustainable as possible [21]. Although techno-economic analysis studies that directly targeting similar campus systems have not yet been reported so far, there are many related research on biogas-linked ecosystems or biomass-based energy systems that are worth discussing. For example, Balázs-Frankó conducted a techno-economic analysis to assess the feasibility of bioethanol production using forest residues with different bark content [22]. Abdullah et al. analyzed the economic performance of several biogas plants based on net present value and energy recovery period [23]. Fábio Codignole Luz et al. used net present value and internal rate of return as basic economic indicators to conduct a techno-economic analysis of Brazilian municipal solid waste gasification power generation technology, they found that the higher the installation capacity of the generator set, the lower the specific cost and at the same time, the more profits [24]. Katherine H. Klavon's research showed that an economically viable anaerobic digestion system can be performed on 250 cattle farms through cost sharing [25]. Ershad Ullah Khan et al. evaluated the polygeneration system based on small biogas plants in Bangladesh by calculating inputs such as cow dung and contaminated water, as well as outputs including biogas, electricity, fertilizer, pure drinking water and so on. The cogeneration system is more competitive and promising than other available technologies [26]. Rasaq. O. Lamidi et al. also studied a biogas-driven combined cooling, heating and power generation system and found that the system became uneconomical when the interest rate was above $9 \%$ and the availability was below $80 \%$. In recent years, techno-economic analysis has been extensively applied in the field of agricultural engineering, but as mentioned above, it is rarely used to evaluate the economic viability of a rural eco-campus system.

With the implementation of China's ecological campus biogas projects, various eco-campus models with biogas as a link have emerged $[27,28]$. According to the ecological principle, these rural biogas-linked eco-campus modes organically combine breeding, planting, campus infrastructure and biogas systems to achieve the recycling of materials and energy sources, thus obtaining ecological and sustainable development. With the government's continuous strengthening and optimization of the environmental management of the rural campuses, the techno-economic evaluation of eco-campus systems has practical needs. The purpose of this study is to quantify the input, output, and corresponding economic status of the two rural eco-campus systems to analyze and evaluate the economic sustainability of them. Since these two eco-campuses represent the operating modes of two different agricultural ecosystems with biogas as a link, this comparison can essentially reveal the superiority and improvement potentials of the two modes.

\section{Materials and Methods}

\subsection{System Description}

\subsubsection{Xidazhai Eco-Campus System}

Xidazhai (XDZ) Middle School $\left(108^{\circ} 7^{\prime} \mathrm{E}, 34^{\circ} 40^{\prime} \mathrm{N}\right)$ locates in the hinterland of the Guanzhong Plain in the Weihe River Basin of China. It is a township junior high school with a history of more than 40 years. The school covers an area of 22,695 $\mathrm{m}^{2}$ and a total building area of $8120 \mathrm{~m}^{2}$. The overall area of the school can be divided into four areas: teaching area, extracurricular activity area, employee living area and ecological campus practice base. The school has 86 teachers and 1200 students which can be divided into 24 classes.

The ecological planning of XDZ School adopts the "Pig/Toilet-Biogas-Vegetable" mode, which is implemented in combination with the local traditional aquaculture industry. In northwestern China, some rural middle schools are large in scale, most of their students are boarding in schools, the school produces a large amount of waste every day, and the campus has a relatively large open space, all these characteristics contribute to this special campus design. This model also considers the population of students and teachers, as well as a vegetable plot with an area of $0.067 \mathrm{hm}^{2}$ around the school. The schematic diagram of the "Pig/Toilet-Biogas-Vegetable" model can be found in Figure 1. As shown in Figure 1, the feces produced from school toilet and pig house will be sent to the pretreatment room, 
and then will be sent to the anaerobic digester. The produced biogas will go through the purification process and then be stored in a water seal tank, and finally be used as cooking fuel. Meanwhile, the produced solid and liquid, i.e., biogas digestate and biogas slurry will be transported to the school farm and the farmers will utilize these organic coproducts as fertilizer. All the vegetables and fruits produced in the farm will be transported to the school kitchen.

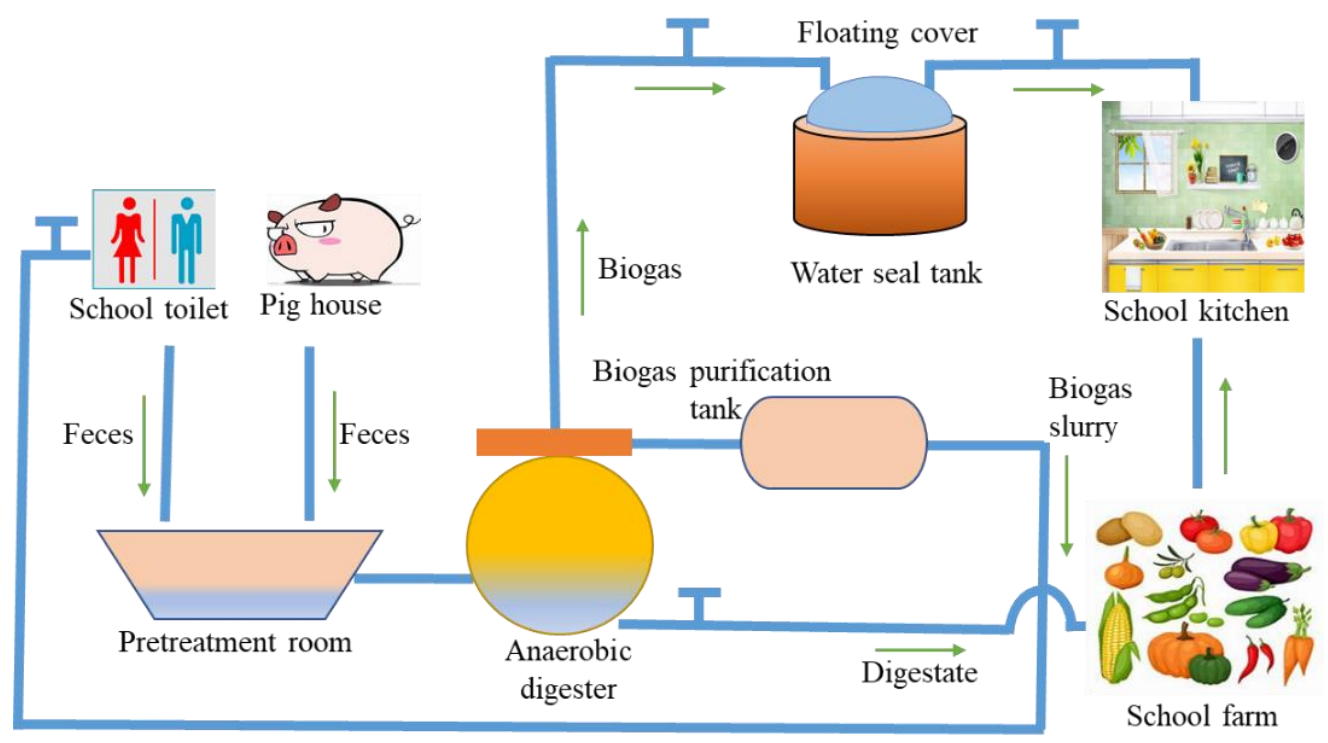

Figure 1. Schematic diagram of the "Pig/Toilet-Biogas-Vegetable" model.

In the "Pig/Toilet-Biogas-Vegetable" model, the "biogas" indicates that the XDZ campus adopting anaerobic digestion technology to process organic wastes inside the campus. In XDZ school, there is a 100-square anaerobic digestion system with a biogas storage cabinet with a volume of $20 \mathrm{~m}^{3}$. The school also has a $200 \mathrm{~m}^{2}$ toilet with an automatic biogas slurry flushing system installed, a $320 \mathrm{~m}^{2}$ solar greenhouse as well as a $60 \mathrm{~m}^{2}$ hog house.

Since the solid content of the manure in school toilets is quite low, it affects the fermentation efficiency of anaerobic microorganisms, and the biogas generated by relying solely on the waste of school toilets is far from meeting the needs. The carbon and nitrogen ratio (an important indicator that shows a certain feedstock's feasibility for being anaerobically digested) of human feces and urine is relatively small compared to other livestock manure, which is not conducive to anaerobic fermentation [29]. Therefore, pig manure with high carbon to nitrogen ratio was selected as another feedstock to solve the problem of nutrient imbalance, which can improve the biogas production of the eco-campus system. In order to avoid the pollution caused by pig manure, the hog house was washed regularly every day, and the wastewater automatically flowed into the biogas system. Digestate will be produced at the same time from the anaerobic digester, which is mostly utilized as an organic fertilizer to promote the growth of crops, all this co-product will be sent to a farm inside the XDZ campus.

\subsubsection{Fanjiazhai Eco-Campus System}

Fanjiazhai (FJZ) Middle School is affiliated to Fengxiang County $\left(107^{\circ} 39^{\prime} \mathrm{E}, 34^{\circ} 53^{\prime} \mathrm{N}\right)$, which is located at the western end of the Guanzhong Plain in Shaanxi, China. It is a newly established township middle school in November 1996 with a total campus area of 30,868 $\mathrm{m}^{2}$ and a building area of $5018 \mathrm{~m}^{2}$. The school now has three grade groups, 18 classes, 1060 students and 65 existing teachers.

In 2005, the FJZ school was identified as a pilot school for the "Shaanxi Provincial Ecological Campus Innovation Project". Starting from raising sheep, producing fruits and vegetables, and building toilets, the school eventually built a pollution-free toilet with an area of approximately $100 \mathrm{~m}^{2}$ and an anaerobic digestion system with a volume of $100 \mathrm{~m}^{3}$, planned a $4200 \mathrm{~m}^{2}$ orchard and grew 
560 fruit trees there. A $100-\mathrm{m}^{2}$ sheep pen and its supporting facilities were also built, more than 50 dairy goats were raised there, and two temporary workers were employed for daily management.

Based on field investigation, it can be found that the dairy goat has strong reproduction ability, low feeding cost, and favorable economic potential. The annual lactation period of dairy goats is around 300 days, and the milk output of one goat is between 600 and $1200 \mathrm{~kg}$. Buying a 6-month-old breeding sheep costs 450 Yuan, the average feeding cost per sheep is 0.44 Yuan per day. In the local area, the feed can be dried corn stalks, soybean stalks, and hay, etc.

The FJZ eco-campus system represents the "Grass-Sheep/Toilet-Biogas-Fruit" mode, which is mainly designed based on campus area, economic foundation and human resources. This mode is especially suitable for promotion in traditional sheep-raising areas, as shown in Figure 2. Similar to the "Pig/Toilet-Biogas-Vegetable" model, the manure from school toilet and sheep farm will firstly go into the pretreatment room, and then be sent the anaerobic digester to produce biogas and digestate. The difference is that the grass planted in the school will be served as the sheep's feed, and in the school orchard there are only vegetables produced. the whole system mainly consists of four parts: campus toilet, anaerobic digestion system, livestock breeding area and school orchard. Taking the anaerobic digestion system as a link, fruit tree planting, sheep raising, grass planting and other industries have formed an ecological campus system. It is common knowledge that planting grass between fruit trees can protect the soil and prevent soil erosion, and at the same time provide feedstock for dairy goats.

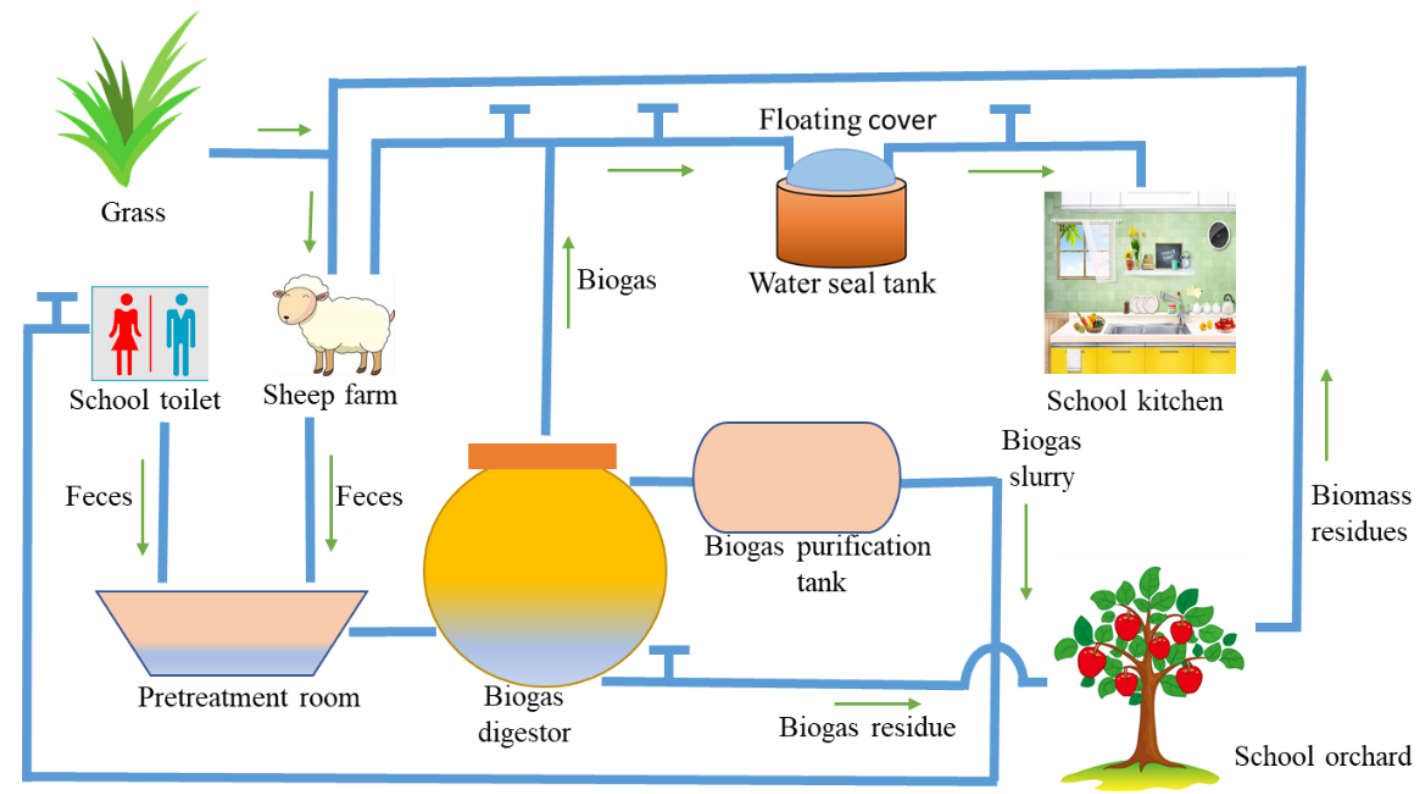

Figure 2. Schematic diagram of the "Grass-Sheep/Toilet-Biogas-Fruit" model.

The main purpose of raising dairy goats is to provide enough feedstock for the anaerobic digester. Since the carbon to nitrogen ratio of sheep manure is quite large, the addition of sheep manure can solve the problem of feedstock shortage and nutrient imbalance caused by human excreta alone as feedstock, thus providing the orchard with high-quality organic fertilizer and reducing chemical fertilizer input. Through foliar application and root application, the co-product biogas slurry can be used to replace a certain amount of pesticide in the FJZ school orchard.

It is worth noting that the transportation logistics can significantly contribute to the costing of overall bioenergy system processes [30]. The mode of transportation is also likely to have significant impacts on the final economic performance of the two eco-campus systems, but in actual life, it's not easy to accurately quantify the transportation distance, fuel consumption and eventually the transportation cost, therefore a reasonable model should be considered for the calculation of transportation affairs. 
Based on previous studies and to fully consider the particularities of the two school systems under study, Equation (1) is used to calculate the transportation cost [31]:

$$
C_{t}=P_{t} \sqrt{\frac{Q}{\rho \pi}}
$$

where $C_{t}$ represents the transportation cost, Yuan (RMB); $P_{t}$ is the unit transportation price, yuan/( $\left.\mathrm{t}^{*} \mathrm{~km}\right)$; $Q$ is the total quantity of the products that need to be transported, $t / y e a r$, and $\rho$ is the distribution density of the products, $\mathrm{t} / \mathrm{km}^{2}$.

To determine the distribution density of the products, the following equation is used [31]:

$$
\rho=\frac{Q}{\pi R^{2}}
$$

where $R$ is the transportation radius, $\mathrm{km}$.

In this study, it's assumed that the feedstock is exactly near the anaerobic digestion system, i.e., the transportation of the feedstock from the farm to the plant is assumed to be zero. Therefore, only the distribution of biogas digestate is considered for the transportation cost determination. On each day once the digestate is produced, all of it will be sent to a local farm through a truck and will be used as organic fertilizer.

\subsection{Economics}

For this economic analysis, a 20 years of system lifespan were considered for both XDZ system and FJZ system in this research. To implement the techno-economic analysis, the initial capital costs and operating costs need to be determined followed by discounted cash flow analysis using the net present value (NPV) approach [32]. The cash flow analysis was carried out using a default discounted cash flow rate (DCF) of $10 \%$. Data from the laboratory research (field investigation), market prices, the literature, and technical reports have been used to estimate these costs for these four eco-campus scenarios, in addition all economic calculations are based on Chinese Yuan (¥). Besides NPV, other commonly used techno-economic indicators for decision making, such as the ratio of output and input (ROI) and the payback period were also used.

NPV is one of the most important methods in capital budgeting, in simple terms, NPV is defined by the difference between the present value of future cash inflows and the present value of future cash outflows, it is generally considered that the larger the NPV of an investment project, the better the profitability of the project. According to [33], NPV is calculated by Equation (3):

$$
\mathrm{NPV}=\sum_{t=1}^{T} \frac{C_{t}}{(1+d)^{t}}-C_{0}
$$

where $T$ is the lifespan of the system, $C_{t}$ is the net cash flow at year $t, C_{0}$ represents the initial capital investment and $d$ is the discount rate.

The Payback period is the time period at which cumulative discounted cash flow value of a project becomes zero, it is defined by the following equation [34]:

$$
\text { Payback period }=t-1+\frac{\left|C D_{t-1}\right|}{D_{t}}
$$

where, $t$ is the year when the cumulative discounted cash flow is positive for the first time, $C D_{t-1}$ is the cumulative discounted cash flow value in the " $t-1$ " year and $D_{t}$ is the discounted cash flow in the " $t$ " year. 
ROI is a performance indicator frequently used to evaluate the efficiency of an investment or compare the efficiency of several different investments [35]. Its calculation can be expressed by the Equation (5):

$$
\text { ROI }(\%)=\frac{P}{I_{0}} \times 100
$$

where $P$ is the annual net profit and $I_{0}$ is the initial total investment.

As described in the above sections, the biogas slurry flushing system is installed in both the two eco-campus systems, therefore, a large amount of water will be saved by substituting tap water, which is significantly beneficial for most arid and semi-arid areas such as northwestern China. In addition, the utilization of bio-digestate in the school orchard replaces a certain amount of chemical fertilizer and pesticide. According to previous studies, it can be known that the school can reduce $53.85 \%$ of the chemical fertilizer and pesticide costs through using digestate, and at the same time improve $7.39 \%$ of the orchard income, which is very attractive for local farmers [36]. Thus, it is valuable to study the cases when these two system credits are considered. Based on these observations, a control scenario is selected for both the two eco-campus systems, i.e., to calculate and analyze the economic performance of the two systems with and without the above credits.

\subsection{Sensitivity Analysis}

During the system design and construction period, there are many factors that would affect the actual operation and comprehensive performance of the eco-campus system. Therefore, a set of variables is selected based on their potential impact on the economic performance. In this study, initial capital investment is a particularly important sensitivity variable due to the uncertainties associated with the evaluation [37]. According to previous studies, the sensitivity was also performed for each factor with $\pm 20 \%$ variation of the base case to identify the most influencing parameter on both scenarios of each eco-campus system [38]. These parameters included fruit yield, biogas price, labor use, digestate yield, biodigester price as well as transportation price.

\section{Results and Discussion}

\subsection{Overview of the Two Eco-Campus Systems}

The scientifically designed ecological campus is of great significance because this kind of campus design has become an important external force, which has a significant impact on students' and faculties' ecological emotions and environmental awareness, as well as enabling students to receive the most intuitive and effective environmental protection education in daily life.

In each of the two rural campuses with thousands of students and faculties, an anaerobic digestion system was built and by which a total quantity of more than $0.3 \mathrm{~m}^{3}$ of biogas was produced per day, the annual biogas production of the anaerobic digestion system was approximately $11,520 \mathrm{~m}^{3}$. According to the local market investigation, the price of biogas was around 1.08 Yuan, if the calculation is based on the quantity of coal substitution in local area, the annual fuel saving of the school is around 12,400 Yuan. The waste in the campus was fully utilized and the methane generated was used for cooking in the canteen, which changed the dilemma of the school only using conventional energy, i.e., coal for cooking, and started to use renewable energy, which avoids the use of many traditional fuels and reduces the possibility of local haze weather.

In dry areas especially in northwestern China, the toilets use a lot of water every year for waste flushing, and the staggering water bill is indeed a huge expense for rural schools. By flushing the toilet with biogas slurry, a lot of water resources can be saved, and the utility fees can be reduced. Through biogas slurry flushing in the school toilet, a $100 \mathrm{~m}^{3}$ anaerobic digester can save 5300 ton of water. The anaerobic digestion system produces 5000 ton of digestate, if the biogas slurry flushing credit is also considered, the total expenses will be reduced by more than 10,000 Yuan. The biogas slurry flushing system uses the biogas slurry as a water source to flush the school toilet instead of the ordinary clean 
water. The system should save water resources on the one hand and keep the toilet clean and tidy on the other hand. The biogas slurry flushing system consists of a sewage pump and flushing control device, which automatically flushes the toilet 6 times a day to keep the space clean. This method saves a large amount of water resources, in addition, the mixing of biogas slurry and human feces plays a role in acidification pretreatment of the feedstock. Specific technological processes of this system are shown in Figure 3.

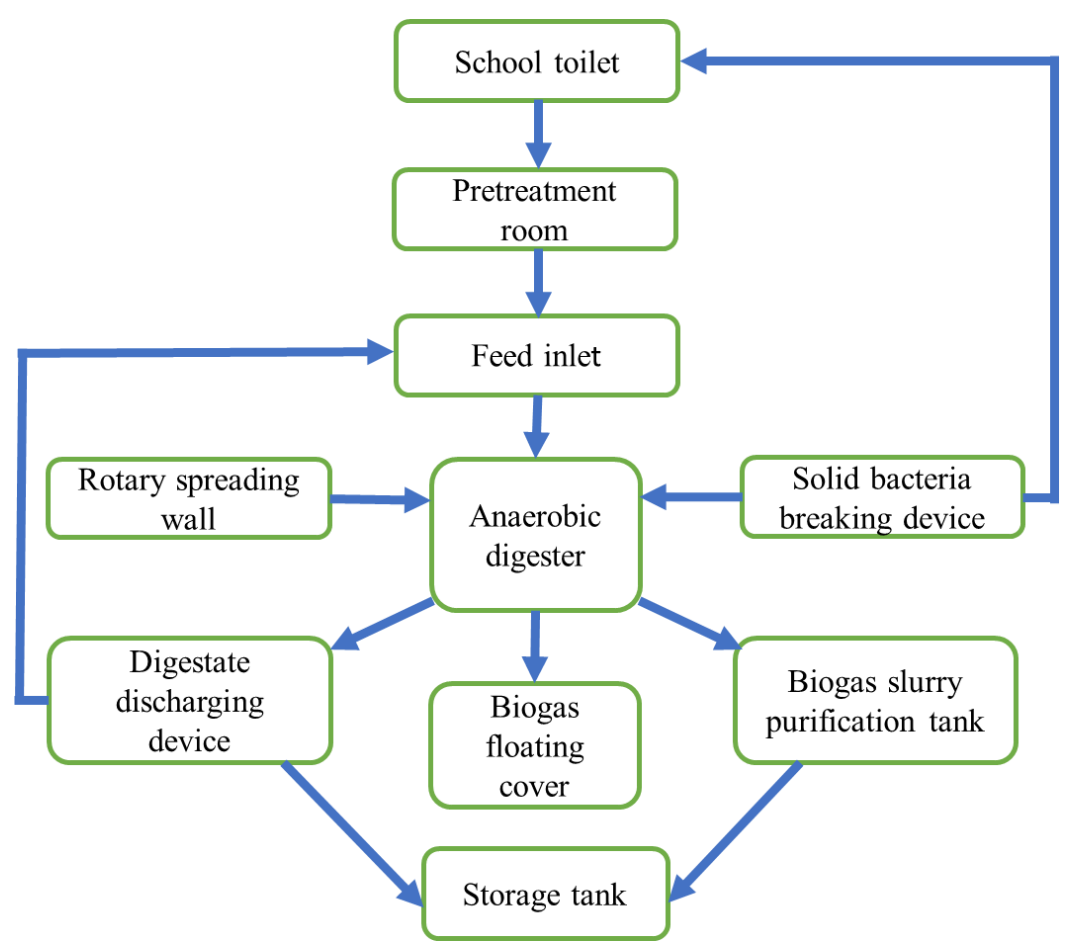

Figure 3. Workflow diagram of the internal circulation of anaerobic digestion system.

Besides rich organic matter, biogas digestate also contains a large amount of nitrogen, phosphorus, potassium and other nutrient elements needed by fruit trees. It is widely regarded as a kind of high-quality organic fertilizer. Based on field observations, applying biogas slurry and digestate makes a remarkable difference for the apple production, the net profits for planting with biogas digestate and with common fertilizer are 348.03 and $315.38 \mathrm{Yuan} / \mathrm{hm}^{2}$ respectively, in average, the utilization of biogas digestate can reduce $53.85 \%$ of fertilizer and pesticide fees, and even improve $7.39 \%$ of the total income [36]. The investigation was also conducted in a local greenhouse, the results show that compared with applying traditional chemical fertilizers, using biogas digestate increased the vegetable yield and simultaneously lowered the costs for daily field management, this made the net profit of the apple orchard increase by approximately $10.35 \%$. It costs a certain quantity of labor force to operate the system every day, especially for dealing with feedstock as well as digestate, it is investigated that the labor force mainly comes from part-time workers with an average labor price of around 15 Yuan/h.

In order to further improve economic benefits, some schools have introduced breeding industry in rural areas and the industry will also be considered as a feedstock source for the biogas-linked ecosystem. In this design process, people will also combine the local traditional breeding habits with the specific conditions of the anaerobic digestion system. For example, the FJZ school has introduced the dairy goat breeding industry and sold the fresh milk at the price of $1.6 \mathrm{Yuan} / \mathrm{kg}$. In addition, the income from lambs can supplement the fund expenditure of the school's breeding industry and therefor form a small virtuous circle system. 


\subsection{Analysis of Investment and Revenue}

Although the anaerobic fermentation systems of the two middle schools are of the same size $\left(100 \mathrm{~m}^{3}\right)$, their input and output characteristics vary greatly due to different operating modes. According to Table 1, it can be found that the initial investment, operating investment and profit of the FJZ system are significantly higher than that of XDZ middle school, the former system is 37\%, $139 \%$, and $71 \%$ larger than that of the latter respectively in terms of the above three indicators.

Table 1. Lifecycle financial statements of the two campus systems.

\begin{tabular}{|c|c|c|c|c|c|}
\hline Accounting Item & FJZ System/¥ & Ratio/\% & Accounting Item & XDZ System/: & Ratio/\% \\
\hline \multicolumn{6}{|l|}{ Initial capital costs } \\
\hline Toilet & 130,000 & 24.25 & Kitchen & 150,000 & 38.46 \\
\hline Biogas digester & 80,000 & 14.93 & Greenhouse & 50,000 & 12.82 \\
\hline Orchard & 30,000 & 5.60 & Hog house and toilet & 130,000 & 33.33 \\
\hline Kitchen & 6000 & 1.12 & AD reactor & 60,000 & 15.38 \\
\hline Sheep pen & 290,000 & 54.10 & & & \\
\hline Total & 536,000 & & & 390,000 & \\
\hline \multicolumn{6}{|l|}{ Lifecycle operating costs } \\
\hline Sheep feed & 221,400 & 23.72 & Insulation membrane & 30,000 & 7.69 \\
\hline Prophylactic repair & 14,000 & 1.50 & Prophylactic repair & 14,000 & 3.59 \\
\hline Utilities & 12,800 & 1.37 & Utilities & 12,800 & 3.28 \\
\hline Transportation & 142,720 & 15.29 & Transportation & 93,440 & 23.94 \\
\hline Labor & 360,000 & 38.56 & Labor & 240,000 & 61.50 \\
\hline Pesticide & 52,400 & 5.61 & & & \\
\hline Fertilizer & 66,800 & 7.16 & & & \\
\hline Fruit bag & 54,800 & 5.87 & & & \\
\hline Others & 8600 & 0.92 & & & \\
\hline Total & 933,520 & & & 390,240 & \\
\hline \multicolumn{6}{|l|}{ Lifecycle revenues } \\
\hline Biogas & 360,100 & 11.04 & Biogas & 356,700 & 18.71 \\
\hline Digestate & 157,000 & 4.81 & Digestate & 156,000 & 8.18 \\
\hline Fruit & 981,400 & 30.08 & Pork & 948,800 & 49.76 \\
\hline Milk & 315,500 & 9.67 & Fruit & 275,000 & 14.42 \\
\hline Lamp & $1,733,600$ & 53.14 & Water saving & 106,000 & 5.56 \\
\hline Water saving & 106,000 & 3.25 & Waste management & 90,000 & 4.72 \\
\hline Waste management & 100,000 & 3.07 & & & \\
\hline Total & $3,262,400$ & & & $1,906,900$ & \\
\hline Total cash flow & $2,328,880$ & & & $1,516,660$ & \\
\hline
\end{tabular}

In operating costs, FJZ middle school has more factors affecting its operation, while XDZ has much less, which reflects the complexity difference of the system to some extent, and FJZ system is proved to be more complex. Specifically, because of the large area of the orchard in FJZ school, more pesticides, fertilizers and other relevant auxiliary materials are needed, while the area of XDZ school is much smaller, so only biogas slurry can meet its growth needs, and no use of pesticides and fertilizers can avoid the formation of environmental pollution in the school. In the FJZ campus system, the operating costs of labor use, transportation and sheep feed are the highest, which are 360,000, 221,400 and 142,720 Yuan respectively. However, in XDZ school, the operating costs of labor use and transportation are the highest which are 240,000 and 93,440 respectively. Therefore, reasonable control of labor and transportation costs is very important for the economic feasibility of the system. In many cases, people will focus more on the initial investment of a project, the operating investment should also be scientifically analyzed and predicted. Labor and transportation costs are relatively high, the main reason is that the daily operation of the anaerobic digestion system requires many manpower to deal with raw feedstock and biogas slurry generated by the system, and the output needs to be 
transported to nearby farms for further use. Of course, the orchard management process also requires a certain amount of labor force and transportation resources.

Inside the two campus systems, although the anaerobic digesters were identical, due to different feedstocks, FJZ system was digesting sheep manure while XDZ system was digesting pig manure, so some certain auxiliary facilities of these two systems were slightly different. As a result, the total investment of FJZ's biogas system became 20,000 Yuan higher than that of XDZ. One indisputable fact is that, for these two campus systems, the infrastructure is the most expensive, including toilets, orchards, greenhouses, kitchens, hog house and sheep pens. The FJZ system is "bigger", so to speak, and there is reason to expect it to be more efficient than the XDZ system.

From Table 1, it could be found that the economic benefits from biogas and biogas digestate of the two campus systems were basically the same, about 360,000 and 160,000 Yuan respectively, but the difference in other aspects of the income was more significant. From the operating investment, it's clear that around 220,000 Yuan was used for sheep feed. This is because the number of sheep raised was relatively large, and the feed was relatively expensive. Of course, the income brought by the lamb was also very favorable, which was approximately 1,733,600 Yuan during the system's life cycle. As the orchard area of FJZ system is much larger than that of XDZ, the fruit income of the former is 3.6 times that of the latter. The gains from water conservation and waste management did not differ much between the two systems, because of the roughly same size of biogas system.

From the perspective of total net income, FJZ Middle School has achieved 1.5 times more profit than XDZ Middle School. However, the assessment of economic benefits should not only consider the net benefits in its life cycle, but also the efficiency of obtaining profits, because efficiency determines whether a project can recover its costs more quickly and obtain stable returns. It is an important factor for investors.

\subsection{Economic Performance Analysis}

This study calculated the results of several typical economic indicators and used them to evaluate and compare the performance of the two eco-campus systems. Figure 4 shows the net present value (NPV) of XDZ and FJZ systems, as well as their NPV results after considering system credits (the two scenarios are expressed by XDZ-C and FJZ-C respectively). The results indicated that the NPV of XDZ system is 127,777 Yuan and 191,675 Yuan before and after considering system credits, respectively. The NPV of FJZ system before and after considering credits were 254,065 and 341,754 Yuan respectively, so the NPV of FJZ middle school was much higher than XDZ, which showed that from the whole life cycle perspective, FJZ Middle School had better economic benefits, which was consistent with the conclusions in the previous sections.

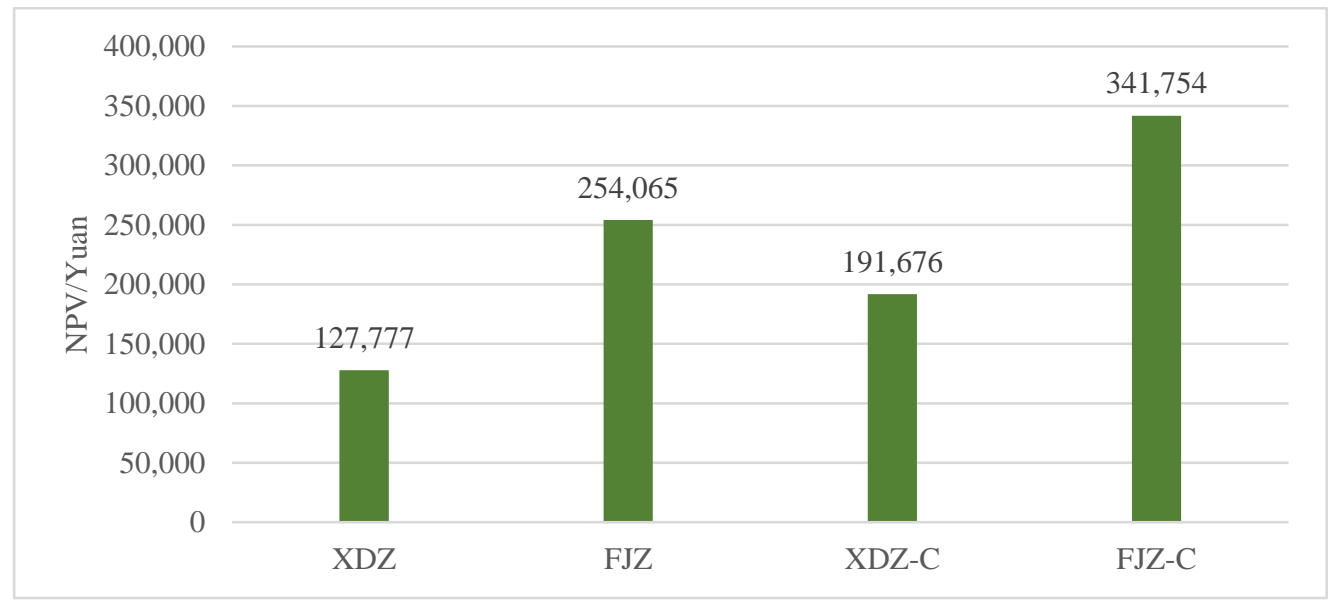

Figure 4. Net present value (NPV) results of the four system scenarios. 
Considering the economic credits brought by biogas slurry flushing and waste management, the impact on NPV was still significant overall. The NPV of XDZ had increased to its 1.5 times, and the FJZ system had increased to its $135 \%$. NPV is positive in all four cases, so it can be initially determined that the two eco-campus systems are economically viable.

In addition to NPV, ROI and payback period are also representative economic indicators often used by researchers. As shown in Figure 5, the ROI of XDZ System and FJZ Middle School were 0.09 and 0.07 respectively. After considering credits, the ROI of both systems increased, with the growing rate of $12.7 \%$ and $9.7 \%$ respectively. The ROI of XDZ middle school is about $20 \%$ higher than that of FJZ, which partly indicates that the former is more profitable and efficient. In addition, the payback time of XDZ System and FJZ middle school is 5.8 and 4.1 years respectively. After considering credits, the payback periods of the two systems are 5.1 years and 4.6 years respectively. The former is still higher than the latter, because of the higher annual return rate of FJZ System. This is consistent with the calculations of many existing biogas ecosystems, for example, the payback periods of a Turkey biogas plant [23] and a Bangladesh biobased poly-generation system [26] were calculated as 3.4 years and 2.6-4 years respectively, which are slightly higher than the two campus systems in this study. Although each system has different boundaries and sizes, in general, most of the similar biogas-linked ecosystems have positive NPV values. In other words, most biogas-linked ecosystems are profitable to some extent.

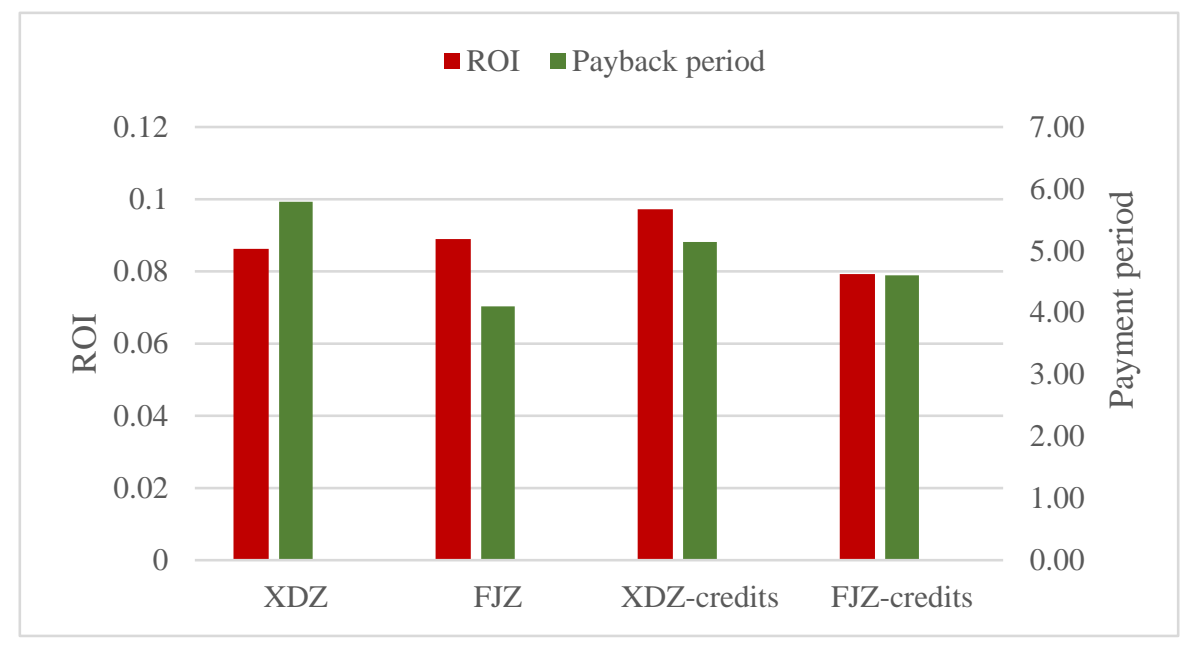

Figure 5. Ratio of output and input (ROI) and Payment period results of the four system scenarios.

Overall, from the perspective of NPV and payback period, XDZ Middle School had lower economic benefits than FJZ Middle School, but from the perspective of production and investment ratio, XDZ Middle School's profit efficiency or earning potential was better than FJZ Middle School.

Therefore, if the initial investment can be controlled well, the "Pig/Toilet-Biogas-Vegetable" model is more suitable for short-term operation, because most systems cannot run for a long period of time for various reasons though the life of the system was assumed as 20 years, while the other agricultural circulating model, "Grass-Sheep/Toilet-Biogas-Fruit", has long-term advantages.

\subsection{Sensitivity Analysis}

In this study, the sensitivity analysis is based on several important factors that have the most significant impacts on the economic performance of the system, and the results are shown in Figure 6. Biogas price was found to be the most significant factor affecting the economic performance of XDZ system. When it fluctuated between plus and minus 20\%, the range of NPV value varied from 98,308 to 157,246 Yuan. Since biogas was the most important product of the system, its price fluctuations would directly affect the large changes in the system's revenue, resulting in a substantial change in the final economic performance. It was followed by the yield of agricultural products and the use of 
labor, their impacts on NPV was basically the same, ranging from $16 \%$ to $17 \%$. At the same time, the profits from agricultural products also contributed a great deal to the eventual economic performance of the system.

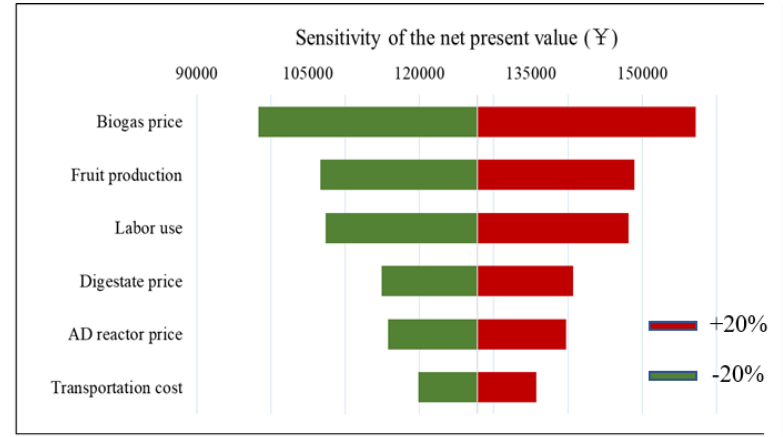

(a)

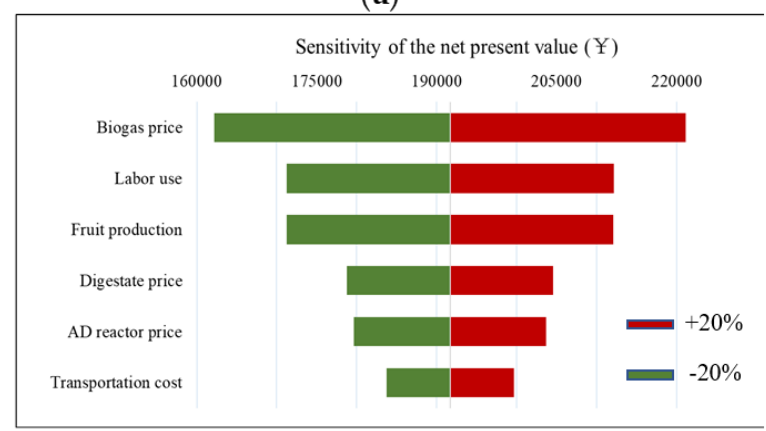

(c)

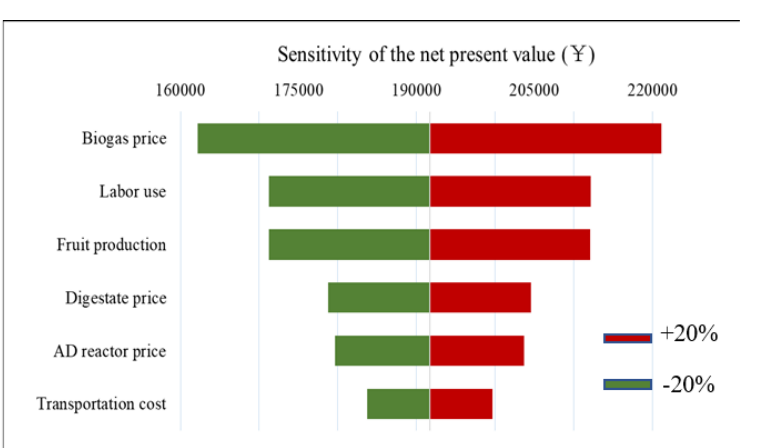

(b)

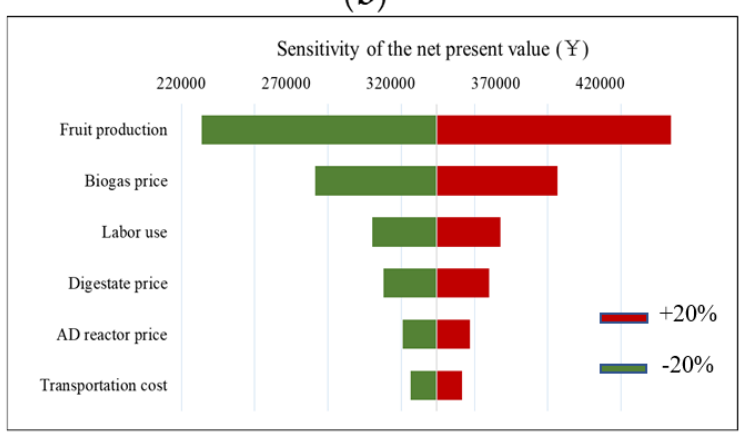

(d)

Figure 6. Sensitivity analysis results of the four campus scenarios. (a) XDZ system; (b) FJZ system; (c) XDZ-C system; (d) FJZ-C system. Note: Green represents $-20 \%$ while red represents $+20 \%$.

As mentioned above, labor investment was the largest of the annual operating costs. The change in the use of labor had a great impact on the economic performance of such systems. Therefore, it is of great significance to rationally regulate artificial labor and mechanical labor. The prices of digestate and anaerobic reactor had a similar impact on the economic performance of the system. The range of changes they caused to NPV was around $10 \%$, with the former having a slightly greater impact. The transportation cost had an impact on the system's NPV of approximately $1 \%$. Compared with other cost items, the transportation had a small impact on the system because of its low unit value and the transportation distance was not very large. After considering system credits, the sensitivity analysis results of XDZ system did not change much, but the impact of labor on economic performance exceeded the fruit yield.

It is obvious that in Figure 6 the sensitivity analysis results of FJZ and XDZ systems were significantly different. In the FJZ system, the greatest impact on NPV was fruit production, followed by biogas prices, and again the labor price. Fruit production caused the system's NPV to fluctuate between 176,950 and 331,180 Yuan in the range of plus or minus $20 \%$. The impact of biogas price and labor use on NPV was not much different, both around $12 \%$. The effects of digestate price, anaerobic reactor price and transportation cost on NPV were $5 \%, 3.2 \%$ and $2.4 \%$ of the original value, respectively, and the impact was relatively small. After considering system credits, the impacts of various factors on NPV had not changed much, but it could be seen that the impacts of biogas price and labor price on NPV were different. Among them, the impact of labor price on economic performance is smaller than that without considering credits. This may be because the system has more profitable products, and it seems that labor prices are not as important as before. 


\section{Conclusions}

A sustainable rural campus ecosystem is an important manifestation of environmental protection education and science popularization education, which requires careful design and planning. The biogas-linked ecosystem is introduced in both two rural campuses, this move can improve the sanitation in school toilets. The system produces biogas slurry, which will be sent to the flushing system to cut the flushing costs by replacing water resources. The use of biogas in the school kitchen also saves a lot of cooking fuel. This study used the technical and economic analysis to evaluate two eco-campus systems with anaerobic digestion technology as the link. The XDZ system represented the "toilet-marsh-vegetable" circular agriculture model, while FJZ represented "Grass-Sheep/Toilet-Biogas-Fruit" ecological cycle model.

By analyzing its specific investment and output composition, we found that during the system planning and design processes, not only the initial investment should be planned, but also the operation forecast and corresponding investment analysis should be emphasized, and the labor and transportation costs should be properly controlled, through this way the operating investment of these systems may be significantly reduced. According to the comparative analysis of NPV, payback period and ROI, it is found that the overall economic profit of XDZ system is lower than that of FJZ system during the whole life cycle, and the latter is regarded as a "bigger" system, but in terms of the efficiency of obtaining economic benefits, the former performs better.

If the water conservation and waste treatment management credits of the two systems are considered, their overall economic benefits will increase greatly. Therefore, if the initial investment can be controlled well, the "Pig/Toilet-Biogas-Vegetable" model is more suitable for short-term operation, because most systems cannot eventually run for a long period of time for various reasons in reality.

The sensitivity analysis revealed that biogas price, fruit production, labor input, biogas residue price, anaerobic reactor price, and transportation cost are the main determinants of system feasibility. Overall, the two campus systems have the most significant three factors, i.e., biogas price, labor price and fruit yield, but they have a large difference in the degree of impact on the two systems.

Author Contributions: C.Z. designed the research, did the investigation works, result analysis, and prepared the manuscript draft. L.Z. supervised data analysis and revised the manuscript. L.Z. and C.Z. collected basic material data. All authors made contributions to the study and writing the manuscript. All authors have read and agreed to the published version of the manuscript.

Funding: The authors gratefully acknowledge the support of the National Natural Science Foundation of China (No. 51609060 and 51879082), the Natural Science Foundation of Jiangsu Province (No. BK20150810), the Postgraduate Scholarship Project of China Scholarship Council (No. 201806300084), the Fundamental Research Funds for the Central Universities (No. 2017B14614).

Conflicts of Interest: The authors declare no conflict of interest.

\section{References}

1. Storms, K.; Simundza, D.; Morgan, E.; Miller, S. Developing a resilience tool for higher education institutions: A must-have in campus master planning. J. Green Build. Winter 2019, 14, 187-198. [CrossRef]

2. Li, X.; Ni, G.; Dewancker, B. Improving the attractiveness and accessibility of campus green space for developing a sustainable university environment. Environ. Sci. Pollut. Res. 2019, 26, 33399-33415. [CrossRef] [PubMed]

3. Camille, W.O.; Washington, G.L.; Julie, N. Campus sustainability in the US: Environmental management and social change since 1970. J. Clean. Prod. 2018, 196, 564-575.

4. Azar, E.; Al Ansari, H. Framework to investigate energy conservation motivation and actions of building occupants: The case of a green campus in Abu Dhabi, UAE. Appl. Energy 2017, 190, 563-573. [CrossRef]

5. Jabbour, C.J.C.; Sarkis, J.; Jabbour, A.B.L.D.S.; Govindan, K. Understanding the process of greening of Brazilian business schools. J. Clean. Prod. 2013, 61, 25-35. [CrossRef]

6. Tan, H.; Chen, S.; Shi, Q.; Wang, L. Development of green campus in China. J. Clean Prod. 2014, 64, 646-653. [CrossRef] 
7. Chen, S.; Lu, M.; Tan, H.; Luo, X.; Ge, J. Assessing sustainability on Chinese university campuses: Development of a campus sustainability evaluation system and its application with a case study. J. Build. Eng. 2019, 24, 100747.

8. Yuan, X.; Zuo, J.; Huisingh, D. Green Universities in China-What matters? J. Clean. Prod. 2013, 61, 36-45. [CrossRef]

9. Ministry of Housing and Urban-Rural Development of the People's Republic of China; Evaluation criteria of green campus; GB/T51356-2019; China Building Industry Press: Beijing, China, 2019.

10. Deng, L.; Liu, Y.; Zheng, D.; Wang, L.; Pu, X.; Song, L.; Wang, Z.; Lei, Y.; Chen, Z.; Long, Y. Application and development of biogas technology for the treatment of waste in china. Renew. Sustain. Energy Rev. 2017, 70, 845-851. [CrossRef]

11. Ho, Y.F.; Chang, C.C.; Wei, C.C.; Wang, H.L. Multi-objective programming model for energy conservation and renewable energy structure of a low carbon campus. Energy Build. 2014, 80, 461-468. [CrossRef]

12. Sangwan, K.S.; Bhakar, V.; Arora, V.; Solanki, P. Measuring Carbon Footprint of an Indian University Using Life Cycle Assessment. Procedia CIRP 2018, 69, 475-480. [CrossRef]

13. Ribal, J.; Fenollosa, M.L.; García-Segovia Purificación Clemente, G.; Escobar, N.; Sanjuán, N. Designing healthy, climate friendly and affordable school lunches. Int. J. Life Cycle Assess. 2016, 21, 631-645. [CrossRef]

14. Larsen, H.N.; Pettersen, J.; Solli, C.; Hertwich, E.G. Investigating the carbon footprint of a university-The case of ntnu. J. Clean Prod. 2013, 48, 39-47. [CrossRef]

15. Townsend, J.; Barrett, J. Exploring the applications of carbon footprinting towards sustainability at a UK university: Reporting and decision making. J. Clean. Prod. 2015, 107, 164-176. [CrossRef]

16. Gu, Y.; Wang, H.; Robinson, Z.P.; Wang, Z.; Wu, J.; Li, X.; Xu, J.; Li, F. Environmental footprint assessment of green campus from a food-water-energy nexus perspective. Energy Procedia 2018, 152, 240-246. [CrossRef]

17. Lambrechts, W.; Van Liedekerke, L. Using ecological footprint analysis in higher education: Campus operations, policy development and educational purposes. Ecol. Indic. 2014, 45, 402-406. [CrossRef]

18. Gottlieb, D.; Kissinger, M.; Vigoda-Gadot, E.; Haim, A. Analyzing the ecological footprint at the institutional scale-The case of an Israeli high-school. Ecol. Indic. 2012, 18, 91-97. [CrossRef]

19. Rajendran, K.; Murthy, G.S. Techno-economic and life cycle assessments of anaerobic digestion-A review. Biocatal. Agric. Biotechnol. 2019, 20, 101207. [CrossRef]

20. Lin, L.; Shah, A.; Keener, H.; Li, Y. Techno-economic analyses of solid-state anaerobic digestion and composting of yard trimmings. Waste Manag. 2019, 85, 405-416. [CrossRef]

21. Shah, A.; Baral, N.R.; Manandhar, A. Chapter four. technoeconomic analysis and life cycle assessment of bioenergy systems. Adv. Bioenergy 2016, 1, 189-247.

22. Frankó, B.; Galbe, M.; Wallberg, O. Bioethanol production from forestry residues: A comparative techno-economic analysis. Appl. Energy 2016, 184, 727-736. [CrossRef]

23. Akbulut, A. Techno-economic analysis of electricity and heat generation from farm-scale biogas plant: Çiçekdağ case study. Energy 2012, 44, 381-390. [CrossRef]

24. Luz, F.C.; Rocha, M.H.; Lora, E.E.S.; Venturini, O.J.; Andrade, R.V.; Leme, M.M.V. Techno-economic analysis of municipal solid waste gasification for electricity generation in Brazil. Energy Conver. Manag. 2015, 103, 321-337. [CrossRef]

25. Klavon, K.H.; Lansing, S.A.; Mulbry, W.; Moss, A.R.; Felton, G. Economic analysis of small-scale agricultural digesters in the united states. Biomass Bioenergy 2013, 54, 36-45. [CrossRef]

26. Khan, E.U.; Mainali, B.; Martin, A.; Silveira, S. Techno-economic analysis of small scale biogas based polygeneration systems: Bangladesh case study. Sustain. Energy Technol. 2014, 7, 68-78. [CrossRef]

27. Wu, H. Biogas Application in New Rural Health Schoolyard Construction. China Biogas 2010, 28, 27-34.

28. Wei, S.; Li, J.; Ma, K. Biogas system on ecological junior middle school in Guangxi Province and the benefits. China Biogas 2009, 28, 39-41.

29. Snell, J.R. Anaerobic digestion: Iii. anaerobic digestion of undiluted human excreta. Sewage Works J. 1943, 15, 679-701.

30. Ascher, S.; Watson, I.; Wang, X.; You, S. Township-based bioenergy systems for distributed energy supply and efficient household waste re-utilisation: Techno-economic and environmental feasibility. Energy 2019, 181, 455-467. [CrossRef]

31. Cao, Y.; Shen, H. A research on collection cost in the process of straw power generation. Power Energy 2012, $33,463-466$. 
32. Imeni, S.M.; Pelaz, L.; Corchado-Lopo, C.; Busquets, A.M.; Ponsá, S.; Colón, J. Techno-economic assessment of anaerobic co-digestion of livestock manure and cheese whey (Cow, Goat \& Sheep) at small to medium dairy farms. Bioresour. Technol. 2019, 291, 121872.

33. Peinemann, J.C.; Demichelis, F.; Fiore, S.; Pleissner, D. Techno-economic assessment of non-sterile batch and continuous production of lactic acid from food waste. Bioresour. Technol. 2019, 289, 121631. [CrossRef] [PubMed]

34. Pradhan, P.; Gadkari, P.; Mahajani, S.M.; Arora, A. A conceptual framework and techno-economic analysis of a pelletization-gasification based bioenergy system. Appl. Energy 2019, 249, 1-13. [CrossRef]

35. Do, T.X.; Lim, Y.I.; Cho, H.; Shim, J.; Yoo, J.; Rho, K.; Choi, S.G.; Park, C.; Park, B.Y. Techno-economic analysis of fry-drying and torrefaction plant for bio-solid fuel production. Renew. Energy 2018, 119, 45-53. [CrossRef]

36. Wang, Y. Studies of Rural Biogas Eco-Campus Model and Evaluation of Its Comprehensive Benefit; Northwest A\&F University: Yangling, China, 2008.

37. Yang, M.; Rosentrater, K.A. Techno-economic analysis of the production process of structural bio-adhesive derived from glycerol. J. Clean. Prod. 2019, 228, 388-398. [CrossRef]

38. Aui, A.; Li, W.; Wright, M. Techno-economic and life cycle analysis of a farm-scale anaerobic digestion plant in Iowa. Waste Manag. 2019, 89, 154-164. [CrossRef] [PubMed]

(C) 2020 by the authors. Licensee MDPI, Basel, Switzerland. This article is an open access article distributed under the terms and conditions of the Creative Commons Attribution (CC BY) license (http://creativecommons.org/licenses/by/4.0/). 